\title{
Roadside advertising and the distraction of driver's attention
}

\author{
Adam Tarnowski ${ }^{1, *}$, Anna Olejniczak-Serowiec ${ }^{2}$, and Agnieszka Marszalec $^{2}$ \\ ${ }^{1}$ Motor Transport Institute, Road Traffic Safety Centre, Warsaw, Poland \\ ${ }^{2}$ Univeristy of Warsaw, Faculty of Psychology, Warsaw, Poland
}

\begin{abstract}
Distraction during driving is becoming a major problem in contemporary transport and traffic psychology. Concentration may deteriorate complex vehicle systems due to the provision of unnecessary information and use of mobile phones (the problem is not only talking but writing text messages and e-mails, browsing sites, etc.). A significant role is also played by advertisers who use aggressive ways to attract attention and communicate product information, especially because they compete with an already overloaded attention system. On the other hand, the need for stimulation is strong with people increasingly less tolerant to monotony. The RoAdvert project is aimed to develop evidence-based rules of placing roadside advertising with respect to safety and real possibilities of regulating the advertising market, including the optimal level of driver stimulation. The paper will present a preliminary analysis of the survey and experimental research.
\end{abstract}

\section{Introduction}

It is generally acknowledged, that attention focus and situational awareness are essential for vehicle driving [1,2], and that attention distraction and overload are key reasons for missing important on-the-road events $[3,4]$. Such errors, called inattentional blindness, pose a serious threat to driving safety [5], with the risk of a crash increasing when the individual's attention capacity decreases[6]. In order to maintain situational awareness, the driver needs to employ a number of cognitive mechanisms: perception, comprehension, memory (i.e. working memory) and anticipation [7,8]. The latter, which actually assumes that the situation changes over time, is based on proper time perception and is thus dependent on attention and cognitive load[9]. Apart from tracking multiple moving objects, the second attention function crucial for driving is detecting changing items in the environment [10]. Research data prove, that attention distraction leads not only to a lack of conscious detection of changes in one's environment, but also to the unconscious perception failure[11]. This is especially true, for peripheral change detection (e.g. a pedestrian or a cyclist entering the car path) while performing attention-demanding primary tasks (i.e. car driving) [12].

Statistical analysis of the number of accidents and behaviour changes reveals some decrease in driver effectiveness in the presence of roadside advertisement [13] which is usually attributed to distraction [14-17] because advertisements compete for drivers' attention. Also, drivers declare higher workloads in the presence of roadside advertising $[15,16,18]$. Research focused on advertisement content, on the other hand, reveals a link

\footnotetext{
Corresponding author: adam.tarnowski@its.waw.pl
} 
between the advertisement's sexual vs. nonsexual appeal and cognitive functioning of people to whom they were presented. It seems that sexual advertisements are not only subjectively assessed and get more attention [19], but they are also better memorized [20,21]. Nonetheless, the performance of cognitive tasks decreases under the influence of sexual advertisements [19], even when memorizing brand-related information included in the advertisement itself is concerned [21].

The above literature review raises a question whether the presence of roadside advertising causes visual attention distraction, increases driver cognitive workload and diverts working memory from the main task, and - if so - whether the drivers' individual attention capacity and advertisement content moderate the effects. The two studies described below were conducted to answer these questions.

\section{Study I}

Study I is a reanalysis of the data gathered during EYEVID project on road infrastructure (PBS1/B6/9/2012). The project developed new evidence based tools for safety inspection of existing roads. The reanalysis is designed to verify the impact of roadside advertising on driver attention. We investigated whether visual noise decreases the amount of attentional resources engaged into a primary task (i.e. car driving), and the influence of this factor on visual system overload.

\subsection{Hypotheses}

It was hypothesized that:

1. In the presence of a roadside advertisement, visual attention distraction increases.

2. Roadside advertisement increases cognitive load while driving.

3. The impact of roadside advertisement on drivers' focus and cognitive load depends on their attention capabilities

a. Drivers with high attention performance are less affected by the roadside advertisement than those with poor attention performance.

\subsection{Participants and procedure}

The data come from 45 active drivers (14 female and 31 male) with a minimal experience of 10 years. Participants' age varied between 28 and $62(\mathrm{M}=42.67 ; \mathrm{SD}=11.91)$. All the participants took part in a 6 kilometre simulated drive and attention test.

Attention was measured with a Pop-Up Test (part of the Test2Drive diagnostic system) [22]. The test is designed to assess two attention functions: searching and identifying crucial objects and lasts about 3 minutes.

The simulated driving was performed in an Opel Astra based AS1200-6 simulator. In the simulator a faithful reconstruction of a 6 kilometre route was programmed. The route consisted of rural and urban roads with high vs. low advertising density. Participants were instructed to drive the car as they usually do and search for service stations. The procedure was as follows: training drive, attention test, test drive.

During the drive, participants' eyes were followed with the use of SMI Glasses $30 \mathrm{~Hz}$. The area of interest for task performance were: road, mirrors, and cockpit. The percentage of time when eyesight was engaged in the areas of interest was counted as a visual attention focus measure, and the average pupil size was used as a cognitive load measure instead of self-description $[23,24]$. 


\subsection{Results}

The results show that the density of advertising affects the percentage of time in which participants' sight was engaged in the areas of interest. The difference between the high advertising density and low advertising density was statistically significant $(\mathrm{F}=23.06$; $\mathrm{p}<0.001 ; \eta 2=0.385)$. For the pupil size no statistically significant effects were observed $(\mathrm{F}=0.346 ; \mathrm{p}>0.05 ; \eta 2=0.013)$. The interaction effects between poor and high attention test performance was insignificant both for dwell time proportion $(\mathrm{F}=0.49 ; \mathrm{p}>0.05, \eta 2=0.017)$, and for the average pupil size $(\mathrm{F}=1.86 ; \mathrm{p}>0.05, \eta 2=0.067)$. The results for dwell time proportion are illustrated in Figure 1 and the results for the average pupil size are illustrated in Figure 2.

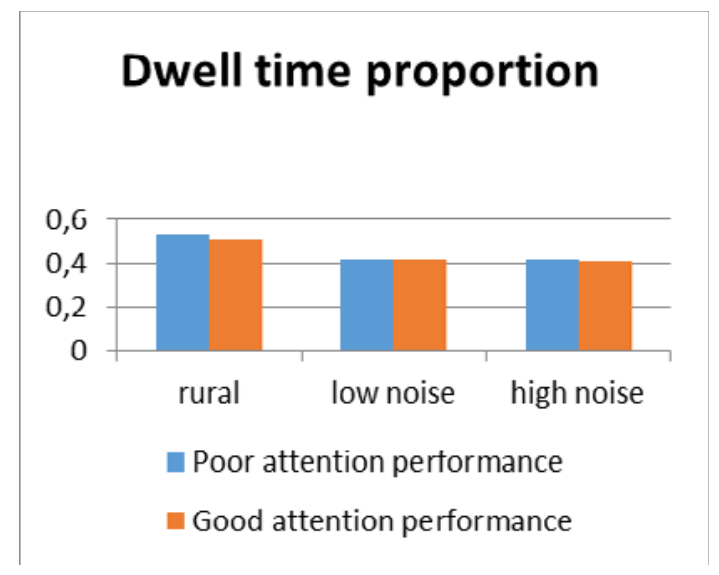

Fig. 1. Dwell time proportion in different conditions divided by attention test performance.

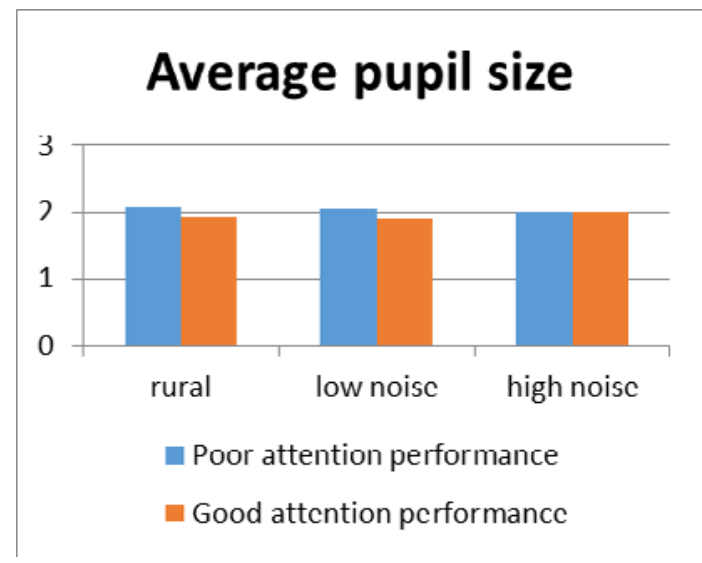

Fig. 2. Average pupil size in different conditions divided by attention test performance.

\subsection{Conclusions}

On the basis of the data presented, it can be concluded that roadside advertising decreases visual attention focus (as stated in hypothesis 1), however it does not necessarily affect cognitive load (contrary to hypothesis 2). No evidence supporting hypothesis 3 was found. 


\section{Study II}

The study's aim was to verify the impact of advertisement contents on memory [25].

\subsection{Hypotheses}

It was hypothesized that:

1. In the presence of roadside advertisements, drivers' working memory capacity decreases.

2. The impact of roadside advertisement on drivers' working memory capacity depends on the advertisement content

a. the presence of human representation in the advertisement decreases working memory performance

b. working memory performance is worse in the context of sexual advertisement than in the nonsexual.

\subsection{Participants and procedure}

The experiment was conducted on 31 (15 female and 16 male) Polish amateur drivers aged from 19 to $45(\mathrm{M}=26.6, \mathrm{SD}=1.3)$. Their average length of driving experience was 7.5 year $(\mathrm{SD}=7.23)$.

The stimuli consisted of 38 photos of driving scenes ( 2 training photos and 36 test photos), some of them including an advertising billboard. In the advertisement-present scenes three conditions were specified: advertisement without human representations vs. with human representation, the latter was then divided into sexual (moderately sexual contents - people wearing underwear) and nonsexual contents. The stimuli was presented for 2 seconds, subsequently, the participant was asked which traffic signs were present in the photo. Sex of the person presented in the advertisement was controlled. The number of errors in the memory task was measured.

\subsection{Results}

The memory test results differed significantly between advertisement vs. no-advertisement condition. Further analyses show that there is also a statistically significant difference between nonhuman and human condition. Almost no differences occurred between sexual and nonsexual contents condition. The tests results are presented in Table 1 and Figure 3.

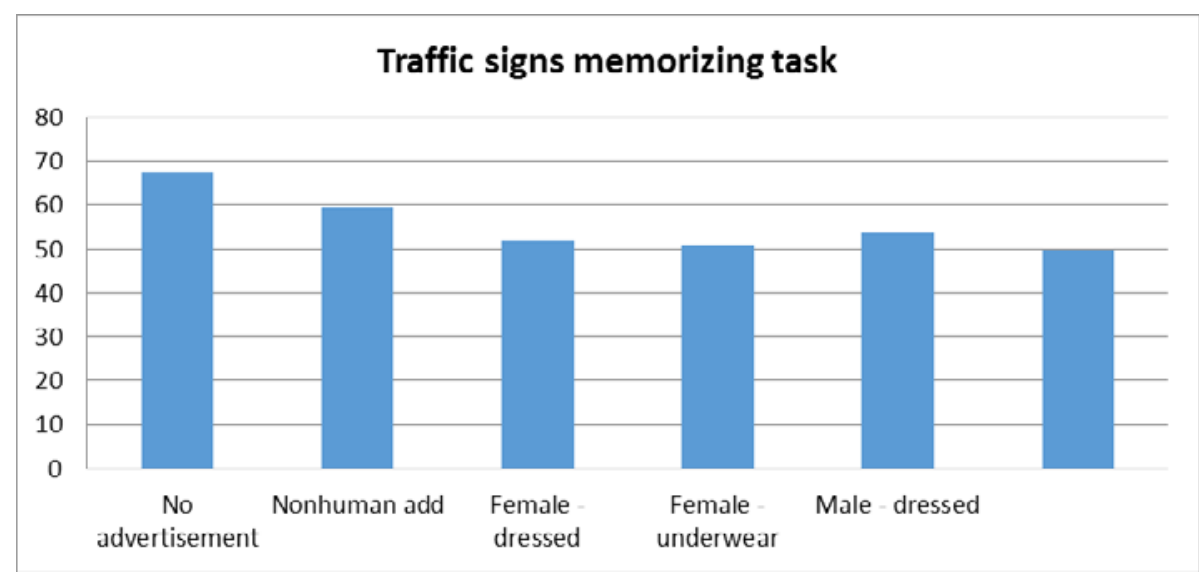

Fig. 3. The presence of advertisement and working memory performance 
Table 1. T-test for dependent samples results - differences between different types of advertising.

\begin{tabular}{|c|c|c|c|}
\hline Conditions pair & T test & $\begin{array}{c}\text { Statistical } \\
\text { significance }\end{array}$ & Effect size \\
\hline No advertisement - Nonhuman add & $\mathrm{t}=-3.80$ & $\mathrm{p}=0.001$ & $\mathrm{~d}=-0.683$ \\
\hline No advertisement - Male underwear & $\mathrm{t}=-10.84$ & $\mathrm{p}=0.001$ & $\mathrm{~d}=-2.067$ \\
\hline No advertisement - Male dressed & $\mathrm{t}=-9.52$ & $\mathrm{p}=0.001$ & $\mathrm{~d}=-1.711$ \\
\hline No advertisement - Female underwear & $\mathrm{t}=-9.78$ & $\mathrm{p}=0.001$ & $\mathrm{~d}=-1.818$ \\
\hline No advertisement - Female dressed & $\mathrm{t}=-10.04$ & $\mathrm{p}=0.001$ & $\mathrm{~d}=-1.947$ \\
\hline Female underwear - Male underwear & $\mathrm{t}=0.77$ & $\mathrm{p}=0.45$ & $\mathrm{~d}=0.138$ \\
\hline Female dressed - Male dressed & $\mathrm{t}=-0.99$ & $\mathrm{p}=0.33$ & $\mathrm{~d}=-0.191$ \\
\hline Male underwear - Nonhuman add & $\mathrm{t}=-7.44$ & $\mathrm{p}=0.001$ & $\mathrm{~d}=1.428$ \\
\hline Male dressed - Nonhuman add & $\mathrm{t}=-3.09$ & $\mathrm{p}=0.004$ & $\mathrm{~d}=0.556$ \\
\hline Female underwear - Nonhuman add & $\mathrm{t}=-5.27$ & $\mathrm{p}=0.001$ & $\mathrm{~d}=-0.966$ \\
\hline Female dressed - Nonhuman add & $\mathrm{t}=-4.98$ & $\mathrm{p}=0.001$ & $\mathrm{~d}=-0.936$ \\
\hline Male dressed - Male underwear & $\mathrm{t}=-2.07$ & $\mathrm{p}=0.047$ & $\mathrm{~d}=-0.392$ \\
\hline Female dressed - Female underwear & $\mathrm{t}=-0.65$ & $\mathrm{p}=0.518$ & $\mathrm{~d}=0.118$ \\
\hline Female underwear - Male dressed & $\mathrm{t}=-1.344$ & $\mathrm{p}=0.189$ & $\mathrm{~d}=-0.247$ \\
\hline Female dressed - Male underwear & $\mathrm{t}=1.768$ & $\mathrm{p}=0.087$ & $\mathrm{~d}=0.317$ \\
\hline
\end{tabular}

\subsection{Conclusion}

The research confirms prior knowledge about roadside advertisement as a potential attention and perceptiveness distractor (hypothesis 1 confirmed). Moreover, the aforementioned results form a basis to conclude that advertisement content does affect driver attention (i.e. working memory), namely, the presence of human representation increases distraction. Moderate sexual context, however, does not reinforce the effect (hypothesis 2 partly confirmed).

\section{General Discussion}

Consistently with prior research, drivers' visual distraction in the context of roadside advertisements was confirmed in the present studies. Their perceptiveness and memorizing - key processes for situational awareness and safe driving - decreased when the roadside advertisement was present. Additionally, some influence of the advertisements' content was observed, which was an increase in distraction when the advertisement included human representation. However, the effect was indifferent to the presence of sexual context. Contrary to the expectations, no moderation effect of attention capacity was observed. This effect, however, may be due to the fact, that crash risk and attention capacity correlation 
observed in older drivers [2] occurs only until a certain level of attention capacity and when the level is reached, further attention capacity increase does not affect driving effectiveness.

\section{Acknowledgements}

The research and the preparation of this article were founded by the National Centre for Research and Development and the General Director for National Roads and Motorways (DZP/RID/I33/4/NCBR/2016).

\section{References}

1. L.J. Gugerty, Situation Awareness During Driving: Explicit and Implicit Knowledge in Dynamic Spatial Memory, J. Exp. Psychol. Appl. 3 pp. 42-66 (1997)

2. A. Cuenen, E.M.M. Jongen, T. Brijs, K. Brijs, M. Lutin, K. Van Vlierden, G. Wets, Does attention capacity moderate the effect of driver distraction in older drivers?, Accid. Anal. Prev. 77 pp. 12-20 (2015). doi:10.1016/j.aap.2015.01.011

3. I.E. Hyman, S.M. Boss, B.M. Wise, K.E. McKenzie, J.M. Caggiano, Did you see the unicycling clown? Inattentional blindness while walking and talking on a cell phone, Appl. Cogn. Psychol. 24 pp. 597-607 (2009). doi:10.1002/acp.1638

4. A. Stinchcombe, S. Gagnon, Driving in dangerous territory: Complexity and roadcharacteristics influence attentional demand, Transp. Res. Part F Traffic Psychol. Behav. 13 pp. 388-396 (2010). doi:10.1016/j.trf.2010.06.008

5. I.D. Brown, Review of the "looked but failed to see" accident causation factor, in: Behav. Res. Road Saf., pp. 116-124 (London, 2002)

6. K.R. Johannsdottir, C.M. Herdman, The Role of Working Memory in Supporting Drivers? Situation Awareness for Surrounding Traffic, Hum. Factors J. Hum. Factors Ergon. Soc. 52 pp. 663-673 (2010). doi:10.1177/0018720810385427

7. M.R. Endsley, Situation Awareness Misconceptions and Misunderstandings, J. Cogn. Eng. Decis. Mak. 9 pp. 4-32 (2015). doi:10.1177/1555343415572631

8. R.A. Block, D. Zakay, Models of psychological time revisited, in: Time Mind, pp. 171-195 (Hogrefe \& Huber, 1996)

9. L.M. Trick *, J.T. Enns, J. Mills, J. Vavrik, Paying attention behind the wheel: a framework for studying the role of attention in driving, Theor. Issues Ergon. Sci. 5 pp. 385-424 (2004). doi:10.1080/14639220412331298938

10. A. Mack, I. Rock, Inattentional Blindness (MIT Press, Cambridge, 1998)

11. D.J. Simons, C.F. Chabris, Gorillas in Our Midst: Sustained Inattentional Blindness for Dynamic Events, Perception. 28 pp. 1059-1074 (1999). doi:10.1068/p281059

12. G. Yannis, E. Papadimitriou, P. Papantoniou, C. Voulgari, A statistical analysis of the impact of advertising signs on road safety, Int. J. Inj. Contr. Saf. Promot. 20 pp. 111-120 (2013). doi:10.1080/17457300.2012.686042

13. A. Smiley, B. Persaud, G. Bahar, C. Mollett, C. Lyon, T. Smahel, W. Kelman, Traffic Safety Evaluation of Video Advertising Signs, Transp. Res. Rec. J. Transp. Res. Board. 1937 pp. 105-112 (2005). doi:10.3141/1937-15

14. S. Bendak, K. Al-Saleh, The role of roadside advertising signs in distracting drivers, Int. J. Ind. Ergon. 40 pp. 233-236 (2010). doi:10.1016/j.ergon.2009.12.001

15. M.S. Young, J.M. Mahfoud, N.A. Stanton, P.M. Salmon, D.P. Jenkins, G.H. Walker, Conflicts of interest: The implications of roadside advertising for driver attention, 
Transp. Res. Part F Traffic Psychol. Behav. 12 pp. 381-388 (2009). doi:10.1016/j.trf.2009.05.004

16. T. Horberry, J. Anderson, M.A. Regan, T.J. Triggs, J. Brown, Driver distraction: The effects of concurrent in-vehicle tasks, road environment complexity and age on driving performance, Accid. Anal. Prev. 38 pp. 185-191 (2006). doi:10.1016/j.aap.2005.09.007

17. D. Crundall, E. Van Loon, G. Underwood, Attraction and distraction of attention with roadside advertisements, Accid. Anal. Prev. 38 pp. 671-677 (2006). doi:10.1016/j.aap.2005.12.012

18. J. Edquist, T. Horberry, S. Hosking, I. Johnston, Effects of advertising billboards during simulated driving, Appl. Ergon. 42 pp. 619-626 (2011). doi:10.1016/j.apergo.2010.08.013

19. T. Reichert, S.E. Heckler, S. Jackson, The Effects of Sexual Social Marketing Appeals on Cognitive Processing and Persuasion, J. Advert. 30 pp. 13-27 (n.d.). doi: $10.2307 / 4189167$

20. J. King, A. McClelland, A. Furnham, Sex Really Does Sell: The Recall of Sexual and Non-sexual Television Advertisements in Sexual and Non-sexual Programmes, Appl. Cogn. Psychol. 29 pp. 210-216 (2015). doi:10.1002/acp.3095

21. L. Samson, The Effectiveness of Using Sexual Appeals in Advertising, J. Media Psychol. pp. 1-12 (2016). doi:10.1027/1864-1105/a000194

22. A. Tarnowski, TEST2DRIVE Podręcznik użytkownika (ALTA, Siemianowice Śląskie, 2016)

23. D. Kahneman, Attention and effort. (Prentice-Hall, New Jersey, 1973)

24. G. Porter, T. Troscianko, I.D. Gilchrist, Effort during visual search and counting: Insights from pupillometry, Q. J. Exp. Psychol. 60 pp. 211-229 (2007). doi:10.1080/17470210600673818

25. A. Marszalec, Unpublished master thesis: Driver attention in relation to roadside advertisement visual content, University of Warsaw, 2016 